\title{
A Novel Technique for the Management of a Maxillary Anterior Alveolar Defect with an Implant-retained Fixed Prosthesis: A Clinical Report
}

${ }^{1}$ Neenu M Varghese, ${ }^{2} \mathrm{~K}$ Harshakumar, ${ }^{3} \mathrm{PT}$ Joy

\begin{abstract}
Successful replacement of the lost teeth by means of tissueintegrated implants represents a major advance in dentistry. The bone quality and quantity available in the anterior maxilla is often variable, and commonly, there is a deficiency of bone volume. Dentoalveolar defects resulting in the loss of the maxillary anterior alveolar ridge is generally a challenge for clinicians. The aim of this clinical report is to describe the prosthetic management of a maxillary anterior alveolar defect with an implant-retained fixed prosthesis. The esthetic and functional requirements of the patient were fulfilled.
\end{abstract}

Keywords: Autogenous bone grafting, Dentoalveolar defects, Fixed prosthesis, Implant, Rehabilitation.

How to cite this article: Varghese NM, Harshakumar K, Joy PT. A Novel Technique for the Management of a Maxillary Anterior Alveolar Defect with an Implant-retained Fixed Prosthesis: A Clinical Report. Int J Oral Implantol Clin Res 2016;7(1):20-23.

Source of support: Nil

Conflict of interest: None

\section{INTRODUCTION}

Anterior dentoalveolar defects caused by trauma, accidents, tumors, periodontal diseases, or even traumatic tooth extractions often result in the extensive loss of alveolar bone, tooth, and gingival tissues, resulting in esthetic and functional difficulties. ${ }^{1,2}$ These patients have always presented the most challenging situations faced by clinicians. ${ }^{3,4}$ There are different treatment modalities to replace missing teeth and soft and hard tissues, such as removable partial dentures, fixed partial dentures, or implant-retained prosthesis. ${ }^{5}$ Esthetics and functional demands have always been a major factor in choosing the treatment options available. Dental implants are nowadays considered as a successful and predictable treatment modality, offering enhanced esthetics and biomechanical

\footnotetext{
${ }^{1}$ Senior Resident, ${ }^{2}$ Professor and Head, ${ }^{3}$ Assistant Professor

${ }^{1-3}$ Department of Prosthodontics, Government Dental College Thiruvananthapuram, Kerala, India

Corresponding Author: Neenu M Varghese, Senior Resident Department of Prosthodontics, Government Dental College Thiruvananthapuram, Kerala, India, Phone: +919495942885 e-mail: neenu.maryvarghese@gmail.com
}

advantages. The increase in their clinical applications has determined a considerable reduction in the use of other treatment modalities, although complicated surgical procedures may be needed, such as bone augmentation, distraction osteogenesis, or sinus lifts for implant placement. ${ }^{1,6}$ This article describes the management of a maxillary anterior dentoalveolar defect in a young male patient with an implant-supported fixed partial denture.

\section{CASE REPORT}

A 20-year-old male patient reported to the Department of Prosthodontics, Government Dental College, Thiruvananthapuram, for rehabilitation of his missing teeth, which was lost following a road traffic accident 9 months back. The patient was systemically healthy with good oral hygiene. Clinical examination revealed the lack of the maxillary anterior residual alveolar ridge, with the loss of 14,13,12,11, 21, 22 in the maxilla and loss of 31, 32, 41, 42 in the mandible (Fig. 1). The patient was reluctant for a removable partial denture; therefore, an implant-supported fixed partial denture was suggested. Following medical and dental evaluation, an initial oral prophylaxis was performed before proceeding with the surgical and restorative procedures.

\section{SURGICAL PROCEDURE}

Clinical and radiographic examination clearly indicated that the height of the alveolar bone in the anterior maxilla

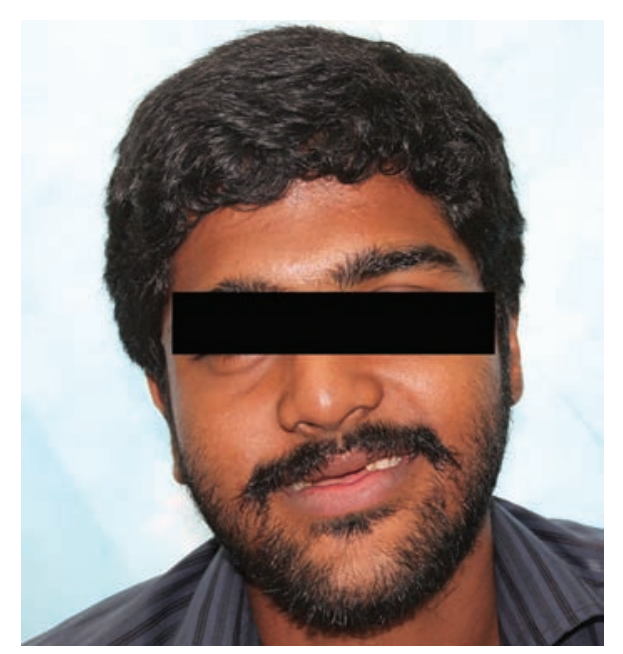

Fig. 1: Preoperative extraoral view 


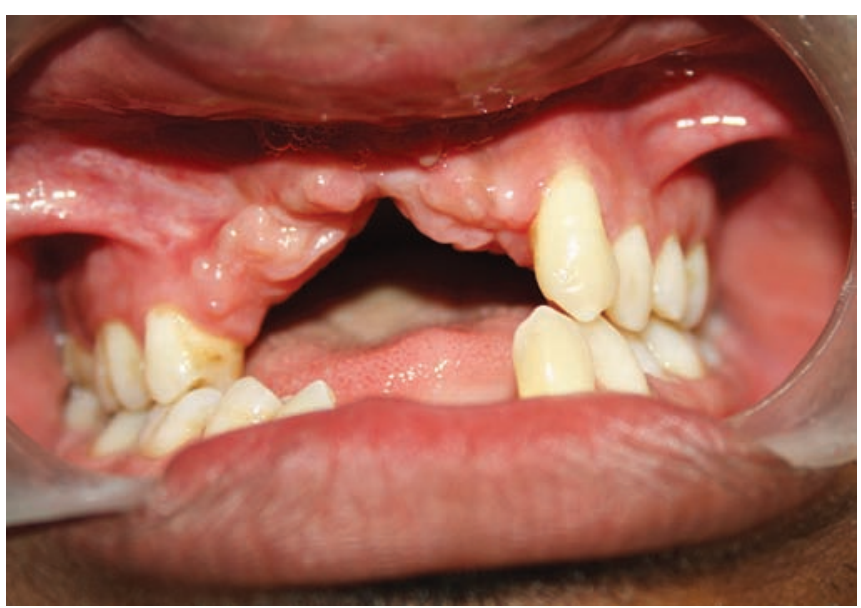

Fig. 2: Preoperative intraoral view

was inadequate for implant placement (Fig. 2). Iliac crest grafting was planned for the patient to prepare the implant site. A staged protocol was planned, involving a delay of 6 months from iliac crest grafting to implant osteotomy. Bone harvesting from the anterior iliac crest involved hospital admission, as it was a far more invasive procedure. Surgery was performed under intubated general anesthesia provided by an anesthesiologist. The medial aspect of the iliac crest was exposed, and an osteotomy outlining the size of the required graft was performed at the iliac crest using a combination of saws, drills, and chisels (Fig. 3). Once the bony block had been obtained, the site was cleansed and Gelfoam was applied to the bony wounds of the iliac crest. The incision was closed and pressure dressings were applied. The intraoral recipient site was exposed, and the harvested piece of block bone was customized to fit the site passively. The corticocancellous bone graft was then fixed to the recipient site. Tension-free flap closure was accomplished with interrupted sutures. Postoperatively, the patient was prescribed antibiotics and analgesics. In addition, the patient was instructed to

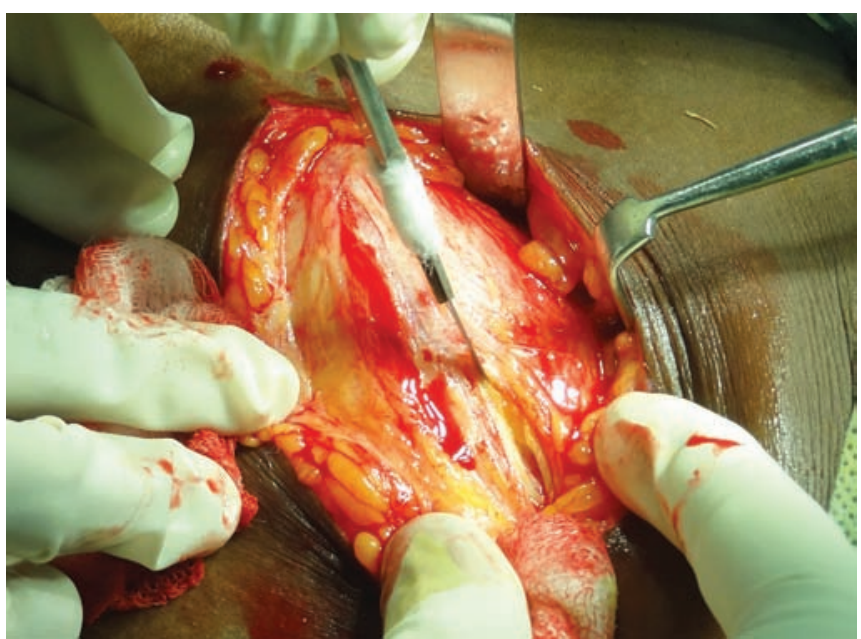

Fig. 4: lliac crest graft donor site

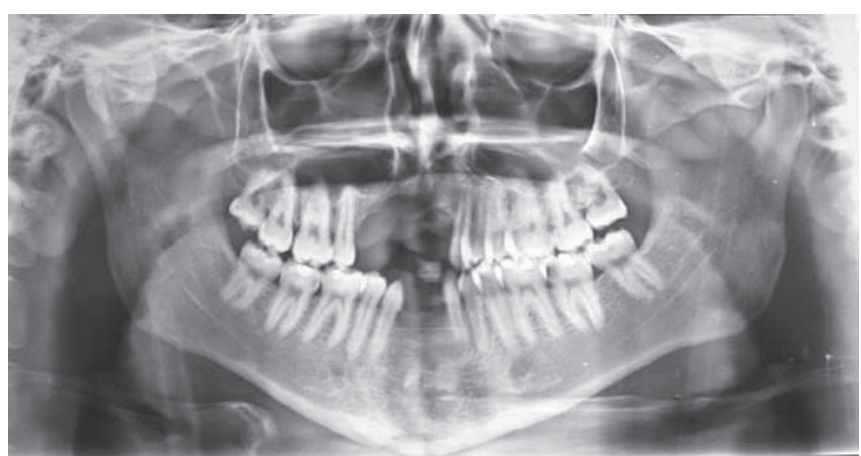

Fig. 3: Preoperative orthopantomogram

rinse with $0.12 \%$ chlorhexidine gluconate solution three times a day for 1 week. After a healing period of 6 months, three implants (Adin Implant System) were planned using a customized surgical procedure. Since the grafted bone was not hard enough to receive an implant drill, a customized osteotome of size $3 \mathrm{~mm}$ diameter was used to prepare the osteotomy sites. Three implants (Adin Implant System) of size $3.5 \mathrm{~mm}$ diameter and $11 \mathrm{~mm}$ length were implanted in the healed grafted bone using the customized osteotomes followed by using bone expanders (Figs 4 to 6). A horizontal ridge augmentation was performed during implant insertion using allogenic graft material. Mucoperiosteal flaps were repositioned and sutured in place. Similar postoperative care was given and a periapical radiograph was taken to examine the implant positions.

After a healing period of 6 months, the implants were exposed. Implant placed at 21 region showed mobility, which was later removed. Healing abutments were connected to the rest of the implants. Two weeks later, the patient was ready for a definitive restoration. Intraoral examination revealed that the soft tissues in the region of the implants had healed well, and radiographic examination showed that the grafted bone appeared to be well integrated with both the maxillary bone and the implants (Fig. 7).

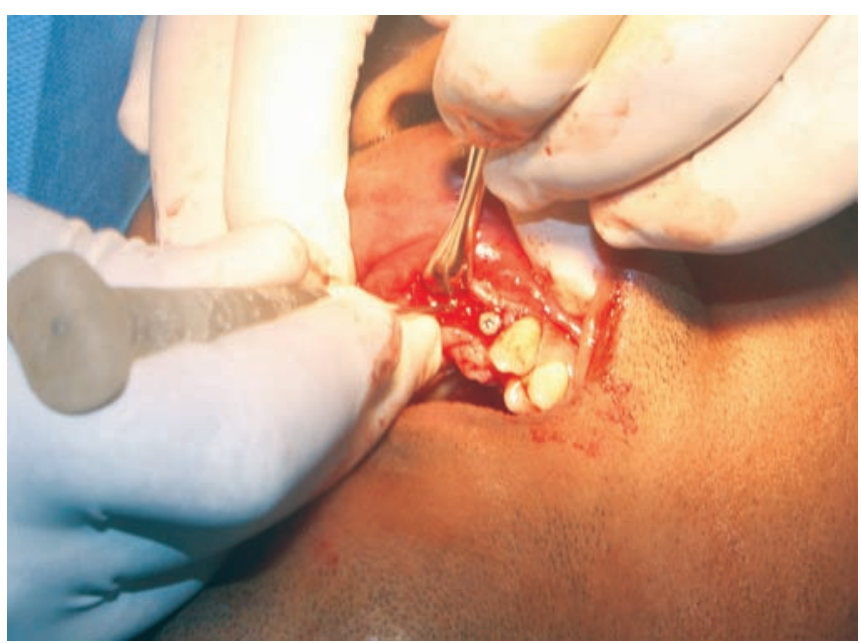

Fig. 5: Implant osteotomy with customized osteotome 


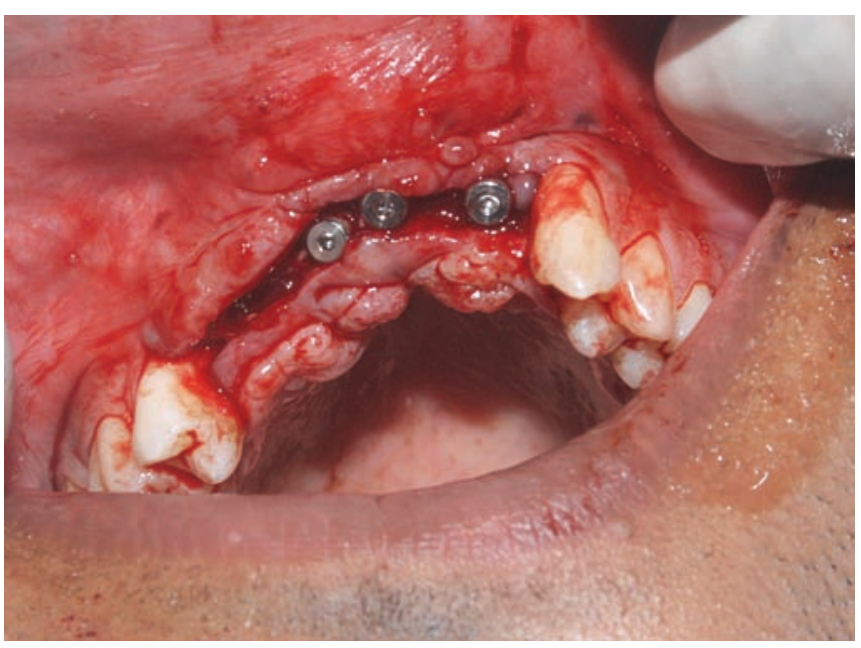

Fig. 6: Placement of implants

\section{RESTORATIVE PROCEDURE}

Six months after the implant surgery, periapical radiographs showed that osseointegration had been undergone successfully. During the prosthetic phase, healing abutments were placed to achieve an esthetic soft tissue emergence profile. After stabilization of gingival tissues, implant abutments were placed and prepared. Left maxillary canine was also included as an abutment and tooth preparation was done. Implant-level impressions were made using putty and light body impression material (addition silicon). A tooth and implant-supported fixed partial denture was constructed involving implants and maxillary left canine. The prosthesis was also constructed with gingival-colored porcelain to compensate the hard and soft tissue loss and enhance the lip support (Figs 8 and 9). The fixed partial denture was then cemented using glass ionomer cement (GC Fugi CEM, GC Corporation, Tokyo, Japan). Finally, a thorough inspection was performed to ensure that the peri-implant sulcus was free of remaining cement particles to prevent any foreign body reactions. Mandibular anteriors were replaced using metal ceramic-fixed partial denture with mandibular canines as abutments. The patient was given oral hygiene instructions including dental floss and

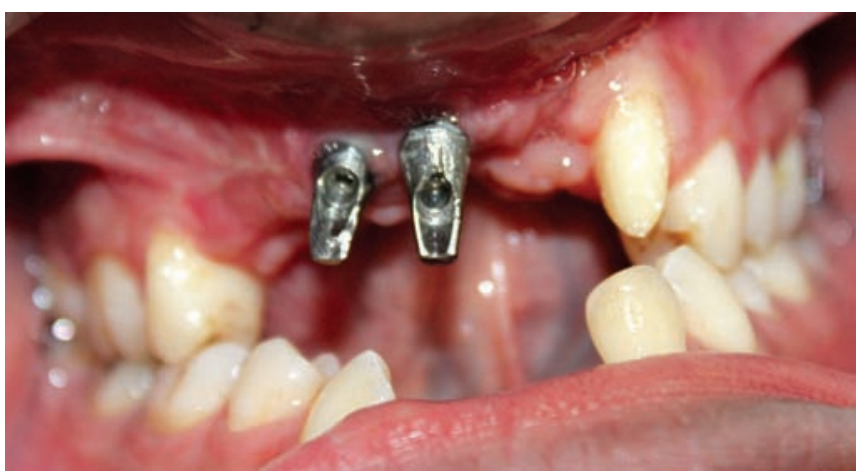

Fig. 8: Abutment preparation

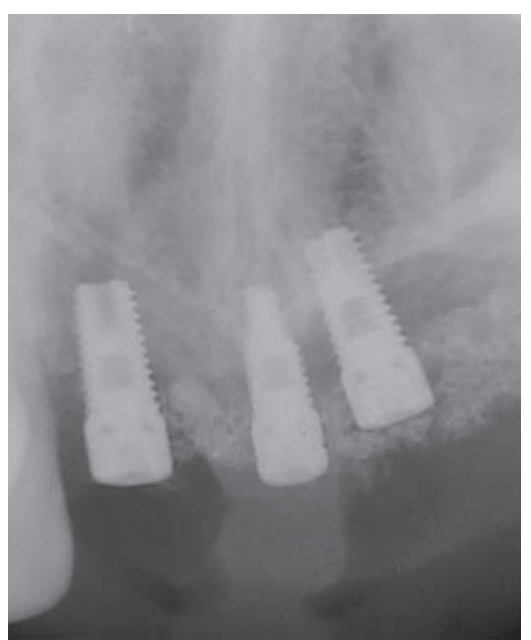

Fig. 7: Postoperative intraoral periapical radiograph

interproximal brushes designed for fixed partial denture. The results were satisfactory both for the patient and for the clinician (Figs 10 and 11).

\section{DISCUSSION}

There are various treatment options available for patients who have severe maxillary dentoalveolar defects. Although removable partial dentures are indicated in such patients, they are not the first choice for the patients who have high esthetic and functional expectations. ${ }^{7}$ Conventional tooth-supported fixed partial dentures is the other option for replacing missing teeth in such patients. ${ }^{8}$ Nowadays, dental implant treatment has become a frequent restorative procedure, offering improved esthetics and biomechanical benefits. ${ }^{9}$

In this case, the patient was fully informed about different treatment options, refused a removable denture option, and the fabrication of implant-supported fixed partial denture was considered to be most acceptable treatment option. Metal ceramic-fixed partial dentures were constructed and gingival-colored porcelain was

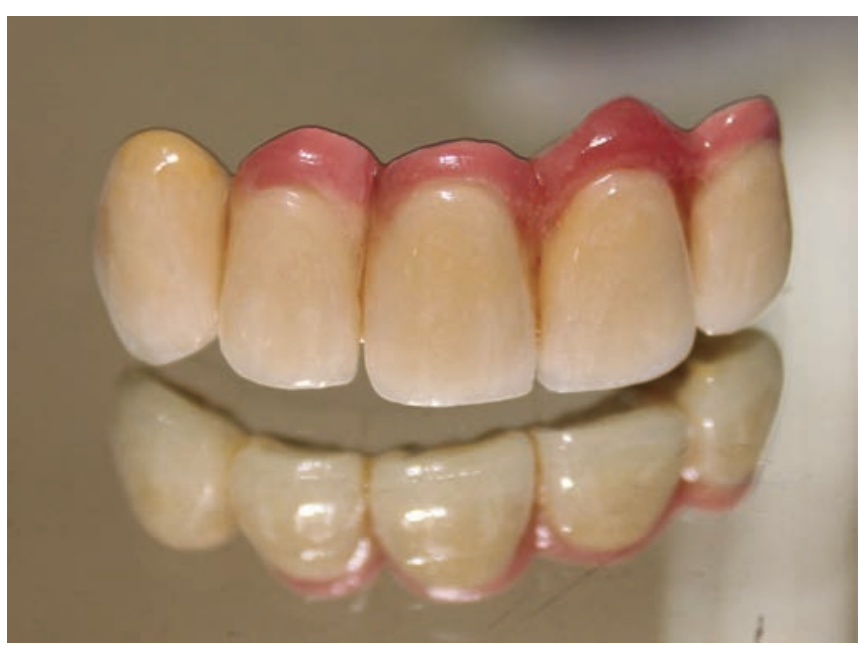

Fig. 9: Finished prosthesis 


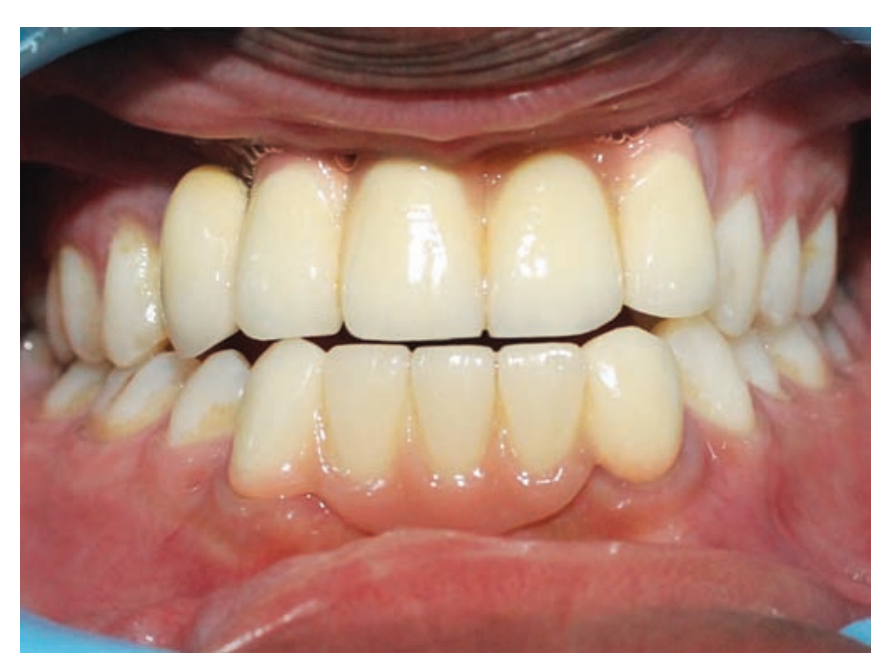

Fig. 10: Postoperative intraoral view

also applied to metal-based ceramic crowns to compensate soft tissues on the maxilla. At the 6-month recall visit, the periodontal tissues were healthy and gingival problems were not observed in the patient, as the importance of oral hygiene procedures on the maintenance and survival of the prosthesis was thoroughly emphasized.

\section{CONCLUSION}

This clinical report described the rehabilitation of missing maxillary anterior teeth and surrounding alveolar bone with dental implants. A metal ceramic-fixed partial denture with gingival-colored porcelain enhanced the esthetic outcome. Despite the limitations of the maxillary anterior alveolar bone, we were successful enough to fulfill the esthetic and functional demands of the patient.

\section{REFERENCES}

1. de Freitas R, Kaizer OB, Hamata MM, de Resende DR, de Oliveira Fortes Kaizer R. Prosthetic rehabilitation of a bone defect with a teeth-implant supported, removable partial denture. Implant Dent 2006 Sep;15(3):241-247.

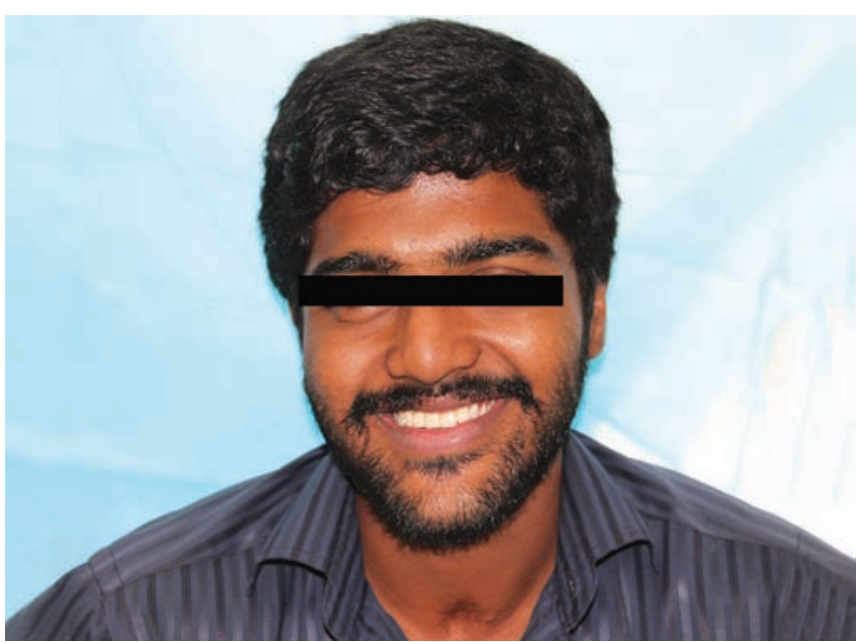

Fig. 11: Postoperative extraoral view

2. Balshi T. Oral prosthodontic rehabilitation for traumatic sports injuries. Dent Clin North Am 1991 Oct;35(4):771-796.

3. Ustün Y, Esen E, Toro lu MS, Akova T. Multidisciplinary approach for the rehabilitation of dentoalveolar trauma. Dent Traumatol 2004 Oct;20(5):293-299.

4. Evren BA, Basa S, Ozkan Y, Tanyeri H, Ozkan YK. Prosthodontic rehabilitation after traumatic tooth and bone loss: a clinical report. J Prosthet Dent 2006 Jan;95(1):22-25.

5. Ugurlu K, Sacak B, Huthut I, Karsidag S, Sakiz D, Bas L. Reconstructing wide palatomaxillary defects using free flaps combining bare serratus anterior muscle fascia and scapular bone. J Oral Maxillofac Surg 2007 Apr;65(4):621-629.

6. Ancowitz S. Esthetic removable partial dentures. Gen Dent 2004 Sep-Oct;52(5):453-459.

7. Frank RP, Brudivik JS, Leroux B, Milgrom P, Hawkins N. Relationship between the standards of removable partial denture construction, clinical acceptability, and patient satisfaction. J Prosthet Dent 2000 May;83(5):521-527.

8. Dhingra K. Oral rehabilitation considerations for partially edentulous periodontal patients. J Prosthodont 2012 Aug;21(6): 494-513.

9. Wiens JP. The use of osseointegrated implants in the treatment of patients with trauma. J Prosthet Dent 1992 May;67(5): 670-678. 
